\title{
USING MULTIPLE SHIFTS TO APPLY CCPM PRINCIPLES IN CONSTRUCTION
}

\author{
Ehab G. Elhosary ${ }^{1}$, Adel I. Eldosouky², Mohamed A. Hakam ${ }^{3}$ \\ ${ }^{1}$ MS Degree Candidate, Construction Project Management, Tanta University, Egypt \\ ${ }^{2}$ Professor, Construction Project Management, Tanta University, Egypt \\ ${ }^{3}$ Assistant Professor, Construction Project Management, Tanta University, Egypt
}

\begin{abstract}
For many construction projects, It is common for the customer to pay an incentive to the contractor for finishing the project in a shorter length of time. In contrast, the contractor pays delay penalties if the project is delayed. Goldratt 1997 suggested critical chain project management method (CCPM) as an attempt for minimizing project duration. Goldratt approach and related buffer sizing approaches result in different values of project buffer and feeding buffer which do not satisfy construction projects circumstances. The proposed model uses multiple shifts and discrete relationship between activity time and cost to be solved by integer programming to express reallife construction projects, optimize project duration with minimum cost and overcome Student's Syndrome and Parkinson's Law. A simplified representation of a small example project is formulated to represent this model. Final solution shows that this method is simple and generates a shorter time at low cost.
\end{abstract}

Keywords: CCPM, multiple shifts, integer programming, discrete relationship between time and cost

\section{Introduction}

Critical Chain Project Management (CCPM) is a novel approach for managing projects developed and publicized by Goldratt (1997). The critical chain target is to execute the project as planned without exceeding the project deadline. Critical Chain Method offers advantages over the traditional CPM scheduling method. The major difference between critical chain method and critical path method is that the uncertainty of activity duration and limited resources are additionally considered in critical chain method (Wuliang et al, 2013).

The first step for CCPM consists of developing an initial schedule for the project activities with their duration estimates (95\% likelihood of completion). This is done while taking into account the dependencies among the activities (as reflected in the project network) and the availability of resources. Since at least some of the resources have limited availability, the resulting schedule is likely to be longer than the schedule obtained with the Critical Path Method, as critical activities are delayed while waiting for the resources they require. At this point CCPM identifies the "Critical Chain" as the set of activities that results in the longest path to project completion after resource leveling. The critical chain yields the expected project completion date. So far CCPM is the same as conventional project management except for the terminology "Critical Chain" which would otherwise be called the "Leveled Critical Path"(Raz, 2001). The next step in CCPM planning consists of recalculating the project schedule based on shortened activity duration estimates. The rationale of CCPM for shortening the original duration estimates is as follows:-

1- Reduce individual activity estimates by 50 percent. The difference between $95 \%$ and $50 \%$ durations is called Buffer Goldratt (1997).

2- Set Feeding buffer (FB) (half of the summation of non-critical chain activities buffers) at points where non-critical chain intersects the critical chain.

3- Set Project Buffer (PB) (half of the summation of critical chain activities buffers) at the end of critical chain.

The main problems addressed by CCPM are:-

1- Estimating safety time: when planners calculate the duration estimations based on their experience, most of planners tend to add hidden safety duration into their estimations for any uncertainty (Leach 2000).

2- Student's Syndrome: Similar to when students are given assignments, they usually start assignments at the last minute even the length of time are enough. This leads to wasting any buffers built into individual activity duration estimates (Leach 2000).

3- Parkinson's Law: People will simply adjust the level of effort to keep busy for the entire activity schedule. Usually, people do not promote be early even they can finish the work ahead of schedule (Leach 2000). 
4- Multi-tasking: the effect of multitasking should be considered because that fragmentation of resource and equipment's set up time would cause activities to delay due to loss of concentration (Hegazy2002).

\section{Research Motivation}

Many attempts to improve Goldratt method initiated the development of new approaches concerning buffer sizing techniques. Literature review of CCPM and related buffer sizing approaches show that CСPM has advantages and disadvantages as detailed next.

Prajapati and Yadav 2017, summarize the advantages of CCPM as the following:-

1- It will be resulted into faster completion of projects than any other scheduling techniques.

2- It is based on resource dependencies to insure that non-critical activities will not become critical in future, that mainly happen in traditional method due to avoidance of resources required for project.

3- It will ensure elimination of multi-tasking within the given project. This can be made by identifying resource conflicts and resolve them by starting with the activity that is closest to the project completion date or with the activity that shows most resource conflict.

4- It is flexible than the traditional method.

5- It considers human behavior during scheduling so improving workers attitude within project environment.

6- It will provide very simple way of tracking and monitoring project progress.

Disadvantages of CCPM are summarized as the following:-

1- Goldratt method cut $50 \%$ of each activity duration as a safety time but this percentage does not satisfy construction projects. Sharma and Yadav 2017, mentioned that if focusing on the specific construction industry projects then the method of calculation of project buffer is not appropriate.

2- Critical chain method requires the noncritical activities to be executed as late as possible to minimize any work in process and reduces behaviors called "student syndrome" and "Parkinson's law" (Kendall et al. 2001). However,
Peng et al 2012 presented a revised critical chain method for the projects which is defined as active critical chain method (ACCM), where all activities are scheduled as early as possible to avoid the risk of project delay in software development projects.

3- CCPM reduces project duration without any consideration of project cost.

Disadvantages of CCPM show that we cannot depend on this method to minimize construction projects duration. To overcome disadvantages of CCPM related to the construction projects, the authors propose:-

1- Time cost trade-off and multiple shifts are used to minimize construction project duration with minimum cost especially in case of constrained completion date, limit availability of resources especially machines, and site congestion. Activity discrete relationship between time and cost is used to express real life construction projects circumstances.

2- Non-critical activities will be scheduled in their early start dates to avoid any delays in project completion date.

3- Using constrained related activities in shifts to overcome multitasking. Shifts system can be applied in case of two or three constrained related activities. Each shift can be used for execution one activity.

4- Realizing of project importance and its value and working 24 hours a day in multiple shifts system are motivation for labors not to waste time and concentrate on finishing activities in their time. So, multiple shifts can be used to overcome Student's Syndrome and Parkinson's Law.

\section{Time-Cost Trade-off Problem}

The objective of time-cost trade-off is to minimize project duration with minimum cost. This section discusses on determining applicable method for project compression, discrete activity time-cost relationship, and using multiple shifts in construction projects for minimizing project cost.

\section{1 Discrete Time-Cost Relationship}

The discrete time-cost trade-off problem, which was introduced by Hindelang and Muth (1979), is 
an important subject in project scheduling theory and applications.

The discrete time-cost trade-off assumes that each activity in the project has several alternative construction methods, and that each method has its own duration and cost (Chen and Weng, 2009). This assumption is justified because an activity can have alternatives to be executed with different methods, crews, equipment, etc. Of course, each alternative has its corresponding cost and duration.

Eldosouky et al. (1991) used two examples of the most repetitive construction activities (excavation and/ or placing concrete) to identify the realistic relationship between the duration and cost for construction activities with different working conditions such as multiple shifts, increasing resources and working overtime. It has been proven that the discrete relationship is the correct representation of the relation between the duration and cost of a construction activity.

\subsection{Project Compression using Mathematical Methods}

The main concept is to formulate the problem in a systematic procedure that must take the standard form of mathematical programming.

Mayer and Shaffer 1965, introduced zero-one variables; to insure that only one of the discrete points (X)s exists in the solution. The duration and cost of activities are given by:

$$
\begin{aligned}
& \text { (C) } i=(\mathrm{C} 1) i+\left\{\sum_{\mathbf{j}=2}^{\mathrm{m}}(\mathrm{Cj}-\mathrm{C} 1) \mathrm{Xj}\right\} \boldsymbol{i} \\
& \text { (d) } i=(\mathrm{d} 1) i-\left\{\sum_{\mathbf{j}=2}^{\mathrm{m}}(\mathrm{dj}-\mathrm{d} \mathbf{1}) \mathrm{Xj}\right\} \boldsymbol{i}
\end{aligned}
$$

Where, $\mathrm{m}$ is the number of discrete points for the activity ( $\boldsymbol{i}$ ). Subtracting (C1) and (d1) from each (C) and (d) in equations (1) and (2) respectively, means that zero-one variables corresponding to the discrete point number (1) is extracted in these equations. Thus reducing number of variables for each activity by (1), $\mathrm{Xj}$ is zero-one variables of activity $(\boldsymbol{i})$.

However, Eldosouky et al. (1991), determined the cost of an activity (C)j in terms of zero-one variables as follows:

Or

$$
(\text { Cost })_{j}=C_{j 1} X_{j 1}+C_{j 2} X_{j 2} \ldots \ldots+C_{j K j} X_{j K j}
$$

$$
(\text { Cost })_{j}=\sum_{k=1}^{k j} c_{j K} X_{j K}
$$

Where, $C_{\mathrm{jK}}$ is the kth direct cost of activity ( $\mathrm{j}$ ), $\mathrm{Xj}$ is zero-one variables of activity $(\mathrm{j})$, and $(\mathrm{Kj})$ is the number of discrete points for activity (j).

\subsection{Utilization of Multiple Shifts in Construction Projects}

The utilization of multiple shifts schedule is very effective and potential solution at reducing project duration. Multiple shifts involve hiring second and third crews of workers to work after the first crew. The utilization of multiple shifts is reported to provide a number of advantages, including (1) doubling or tripling weekly work-hours; (2) lowering the required premium costs for evening and/or night shifts compared to those of overtime hours; (3) Lack of immediate fatigue factors compared with working overtime; and (4) No congestion factors resulting in overmanning (Hanna et al. 2008).

Despite these advantages, the utilization of multiple shifts still has a number of limitations including its negative impacts on construction, cost, productivity, and safety. Accordingly, the utilization of evening and night shifts is reported to cause: (1) Productivity losses due to workers fatigue, health disorder, and lower morale (Kogi 1985). (2) Increasing the risk of injuries and accident rate (Folkard and Tucker 2003). (3) Little cooperation between shifts, inconsistent operating procedures across shifts, inefficient communication between crews, and absence of regular business hours for management (Penkala 1997).

These are important factors which can impact on project performance and cost, but if there is a large and important projects that require work beyond a standard shift and there is the ability to perform work at night, shift work can be useful. This is especially true for extremely hot climates, where productivity at night when the temperatures are cooler is actually higher than during the day. (Hanna et al. 2008).

\subsection{Impact of shift work on labor productivity}

In general, the productivity losses due to shift work come from supervisory, coordination and transition problems. This makes it hard to quantify the actual amount that it will affect a project and it is dependent on the organization and type of work. The reason shift work has not been used is because 
its application is limited. It practically should be used on larger projects, where shift work would be used for an extended period of time (Ibbs 2015).

However, Waldron 1968, estimated the productivity loss due to shift work to be $10 \%$. On the other hand, total project cost of shift work is normally higher than that of normal operation. Shift work introduces other additional costs, including additional administration personnel, supervision,

quality control, safety, and lighting. Direct costs of shift work are approximately $20 \%$ extra in wages (Hanna etal, 2008).

\subsection{Using multiple shifts in construction projects in Egypt}

Interviews with more than twenty Egyptian engineers project managers, site managers, site engineers, and supervisor engineers in different construction projects such as infrastructure, residential, electric substation, oil and gas projects highlight that:-

1- Using multiple shifts of activities that are executed depending on machines as main resources is very useful because of low temperature, easy movement in the site, and traffic flow. Also, most engineers mention that production rates do not change in the second shift and third shift. So, machines can work on double or triple shifts without productivity losses with changing labor crews from shift to other. In such activities, daily rates of labors in the second shift and third shift increase by $25-50 \%$ which represents $5-10 \%$ of activity cost. Efficiency and maintenance of machine and their effect on productivity and cost can be considered in the projects.

2- Using multiple shifts of activities that are executed depending on labors as main resources is useful for large projects. Production rates of the second shift decrease by $15-20 \%$ and production rates of the third shift decrease by $25-35 \%$ regarding to the first shift. Daily rates of labors on second shift and third shift increase by $25 \%$ and $50 \%$ regarding to the first shift which represent 10$20 \%$ of activity cost. Some engineers mention that production rates decrease by a small amount between $5-10 \%$ if the system of multiple shifts is maintained for long period of time.

So, the proposed model is formulated depending on the production rate of the evening shifts decreased by $20 \%$ and night shifts by $30 \%$, the activity cost of the evening shift increased by $10 \%$ of the normal cost, and the activity cost of night shift increased by $20 \%$ of the normal cost for activities that use labors as main resources in its execution. Production rates do not change of activities that use machines as main resources in its execution and the activity cost of the evening shift increased by $5 \%$ of the normal cost, while the activity cost of night shift increased by $10 \%$ of the normal cost.

\subsection{Constrained Related Activities in Shifts:}

In general, machines are key resource in construction projects. In some cases, there are two or three activities that are affected by using the same machine as a main resource. These activities are called constrained related activities and must be treated together in planning. Shifts system is used to treat this problem for minimizing project duration and to overcome such constrained related activities. Shifts system can be applied in case of two or three constrained related activities. Each shift can be used for execution of one activity by the same machine.

\section{The Proposed Model Formulation}

The proposed approach includes the following four phases, see Figure (1), which are going to be discussed in detail in this section.

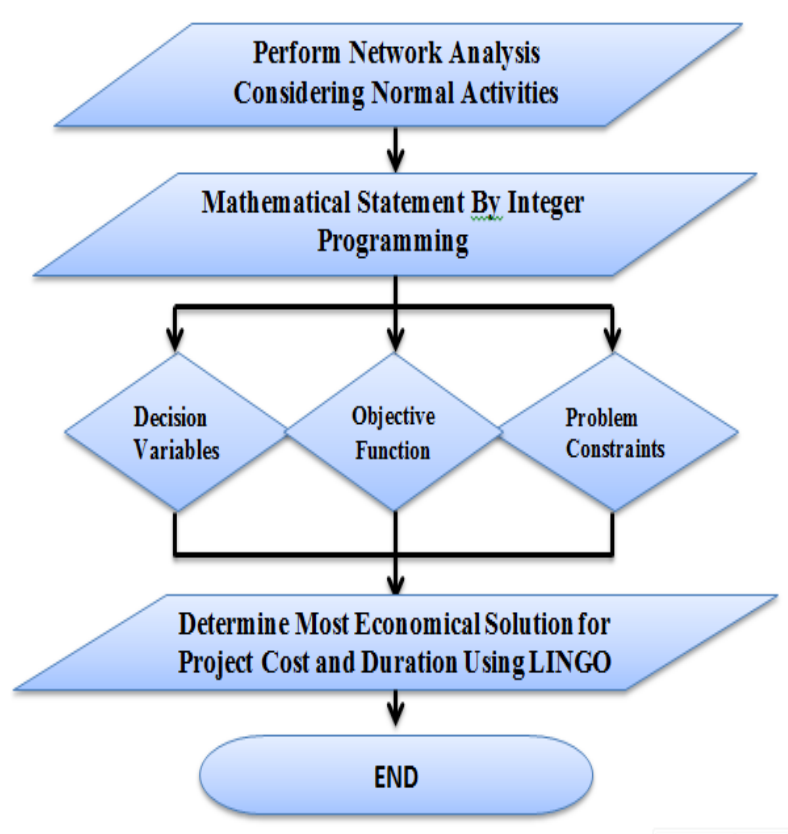

Fig. (1) Flow Chart of the Model 


\subsection{Perform Network Analysis Considering Normal Activities Durations and Costs}

The first step in the proposed model is to perform network time analysis considering normal activities' durations and costs. Activity duration estimates are quantitative assessments of the likely number of time periods that are required to complete an activity. Project management software such as primavera P6 or Microsoft Project can be used for these phase. MS Project software will be used to formulate the proposed model.

\subsection{Mathematical Statement by Integer Programming}

The activities comprising a construction project could be classified into a number of groups according to the key resources which affect the planning of these activities. Each group (i) could contain a certain number of activities. The utility data for each activity (j) could be represented by a number of discrete points. Therefore, the following notations are introduced:

I :number of groups of activities in a project.

Ji : number of activities in group (i), and

$\mathrm{Kj}$ : number of discrete points for activity (j).

\subsubsection{Decision Variables}

In the formulation of the problem, two kinds of decision variables will be used. These are:

ZERO-ONE VARIABLES; (X), and

ACTIVITIES SCHEDULED START; (SS).

An integer variable $(\mathbf{X})$ is introduced which represent choice of one or double or triple shifts of non-related activities and choice of first or second or third shift of constrained related activities, and will have the value of zero or one only.

On the other hand, the activities scheduled start decision variables will be used to satisfy the proper sequence of activities in the project.

\subsubsection{Objective Function}

The objective of the problem is to complete the project within most economical duration by expediting certain activities keeping the overall costs at a minimum. Therefore, the objective function to be minimized is the cost of the project. The cost of an activity $(C) j$, in terms of zero-one variables, could be defined as follows:

$$
\text { (Cost)j }=\sum_{k=1}^{k j} C_{j K} X_{j K}
$$

Where, $\mathrm{C}_{\mathrm{jk}}$ is the kth direct cost of activity (j) The cost of a group (i) is the summation of costs of all the individual activities comprising the group. Therefore:

$$
\text { (Group Cost) } \mathrm{i}=\mathrm{Ci}=(\mathrm{C}) 1+(\mathrm{C}) 2 \ldots+\text {. (C) Ji }
$$

Substituting from Eq. (4) into Eq. (5), the cost of group (i) will be:

$$
\mathbf{C i}=\sum_{\mathrm{j}=1}^{\mathrm{Ji}} \cdot \sum_{\mathrm{k}=1}^{\mathrm{kj}} \mathbf{\mathrm { jK }} \mathrm{j}_{\mathrm{jK}}
$$

So, the direct cost of the project (PDC) is the summation of costs of all groups of activities in the project. Therefore,

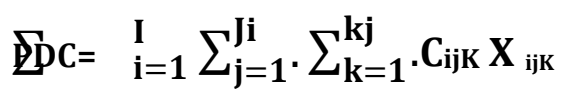

Indirect cost of the project is calculated by multiplying completion time of the project and indirect cost of unit time. The project indirect cost, therefore, is:

$$
\text { Project indirect } \operatorname{cost}=Y^{*} S F
$$

Where, (Y) is the indirect cost of unit time of the project.

(SF) is the required scheduled finish or completion time of the project.

So, the total cost of the project (PC) is the summation of direct cost and indirect cost of the project. The project total cost (PC), therefore, is:

$$
\mathrm{PC}=\sum_{\mathrm{i}=1}^{\mathrm{I}} \cdot \sum_{\mathrm{j}=1}^{\mathrm{Ji}} \cdot \sum_{\mathrm{k}=1}^{\mathrm{kj}} \xi_{\mathrm{K} i \mathrm{ijK}} \mathrm{X}+\mathrm{Y}^{*} \mathbf{S F}
$$

\subsubsection{Problem Constraints}

1- Zero-one constraints: to insure that only one discrete point is considered for each activity. The condition for satisfying this criterion for the activity (j) is:

$$
\sum_{\mathbf{k}=\mathbf{1}}^{\mathrm{kj}} \mathbf{X}_{\mathrm{jKj}}=\mathbf{1}, \mathrm{X} \geq 0 \text {; integer }
$$

Where, (Kj) is the number of discrete points for activity (j).

\section{2-Constrained Related activities:}

The zero-one decision variables could be used also to satisfy the selection of the corresponding discrete points for the constrained related activities. This means that choosing a certain point for an activity in a group of constrained related activities in one of three shifts requires the selection of the points for the other activities in the group to work in the second and third shifts. The constrained related activities that are based on working each activity in 
one of three shifts could be satisfied by the following constraints:

$$
\sum_{j=1}^{i} X j 1=1, \sum_{j=1}^{i} X j 2=1, \sum_{j=1}^{i} X j 3=1
$$

Where, (j) is the number of constrained related activities.

3- Network logic constraints: that will satisfy the proper sequence of activities in the project. Network logic constraints include scheduled start constraints and project completion constraint.

The logic of network can be satisfied by considering a precedence constraint for each activity with its immediate predecessor(s). In total, these precedence constraints determine the project duration, since the project duration is the finish time of last activity in the project.

The duration of an activity (j), in terms of zero-one variables, could be defined as follows:

$$
\text { (D) })_{j}=\sum_{k=1}^{k j} \mathbf{d}_{j K} \quad X_{j K}
$$

Where, $\left(d_{j k}\right)$ is the $k^{\text {th }}$ duration of activity (j).

The scheduled start of an activity (m), (SS), is equal to the greatest scheduled finish of its preceding activities as follow:

$$
\mathrm{SS}_{\mathrm{m}} \geq \mathrm{SF}_{\mathbf{j}}
$$

The scheduled finish of an activity is the scheduled start of the activity plus its duration. Therefore, the scheduled finish for an activity (j) is:-

$$
S F_{j}=S S_{j}+D_{j}
$$

Substituting for SFj we have:

$$
S S_{m} \geq S S_{j}+D_{j}
$$

If there are $\left(\mathrm{NS}_{\mathrm{j}}\right)$ successors for activity (j), Eq.(16) must be considered (NS) times;

$$
S S_{j}+D_{j}-S S_{m} \leq 0 \quad m=1,2, \ldots . ., N S_{j}
$$

Substituting for D, of Eq.(12) into Eq.(16) and rewrite. It gives:

$$
S S_{j}+\sum_{k=1}^{k j} d_{j k} X_{j K}-S S_{m} \leq 0, \quad m=1,2, . ., N S_{j}
$$

The finish time of the last activity (n) is its start time plus its duration. The project completion constraint, therefore, is:

$$
S S_{n}+D_{n}-S F<=0
$$

Where:

SF is the scheduled finish or completion time of the project.

\subsection{Determine Most Economical Solution for Project Cost and Duration Using LINGO}

LINGO is a comprehensive tool designed to make building and solving mathematical optimization models easier and more efficient. LINGO provides a completely integrated package that includes a powerful language for expressing optimization models (LINGO.com 2017). To get results without any fractions, it should add to the model generate integer variables which can add in LINGO program as the following appreciations:

$\mathrm{GIN}\left(\mathrm{X}_{1}, \mathrm{X}_{2}, \ldots . . . . \mathrm{etc}\right.$ ) for Zero-One constraints. GIN ( $\mathrm{SS}_{\mathrm{A}}, \mathrm{SS}_{\mathrm{B}}, \ldots . . . \mathrm{etc}$ ) for Scheduled start constraints Where GIN $\mathrm{X}_{1}$ is the abbreviation of generate integer for variable $\mathrm{X}_{1}$

Project duration is determined as the scheduled finish or completion time of the project (SF). It is the optimum duration which is associated with minimum project cost.

\section{EXAMPLE OF PROBLEM FORMULATION}

For the purpose of demonstration of problem formulation, consider the simple project represented in Fig. (2) (Lawrence 2014). The project consists of (13) activities. The project is divided into (4) groups. The first, second, and third groups have (3) constrained related activities for each group while the fourth one has (4) non-related activities.

\subsection{Project Utility Data}

1- UTILITY DATA TABLE; which includes groups of activities and utility data for each activity. Data for an activity contains its durations and the corresponding costs. The first point belongs to the normal duration and cost, while the last point refers to the crash duration and cost. The durations and direct costs are given in table (1). The durations; (d), are given in days and the costs; (c), are given in Egyptian pound (LE).

2- INDIRECT COST; Indirect cost of the project is assumed to be LE.5000 per day. So, the indirect cost of the project for project duration of 85 days is LE.425000. 


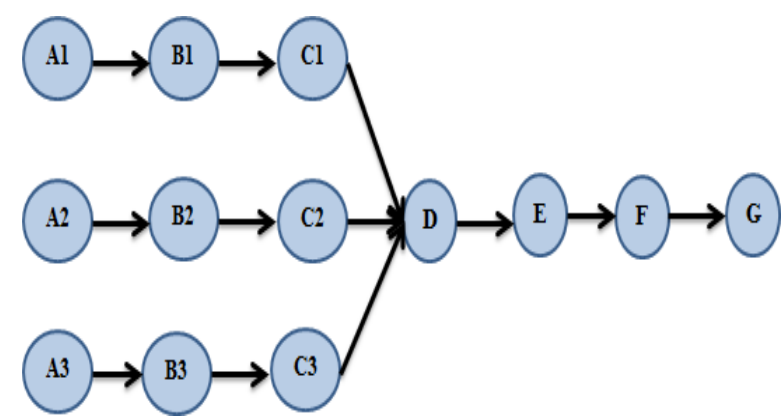

Fig. (2) An Example Critical Path Project
The simple project was previously solved using Goldratt method as shown in figure (3). Figure (3) illustrates that project activities durations decreased by $50 \%$. The Critical Chain contains activities A3, A2, A1, B1, C1, D, E, F, and G with total duration 55 days. Project buffer calculated as half of critical chain duration 28 days. So, project duration is equal the summation of critical chain duration and project buffer as 83 days.

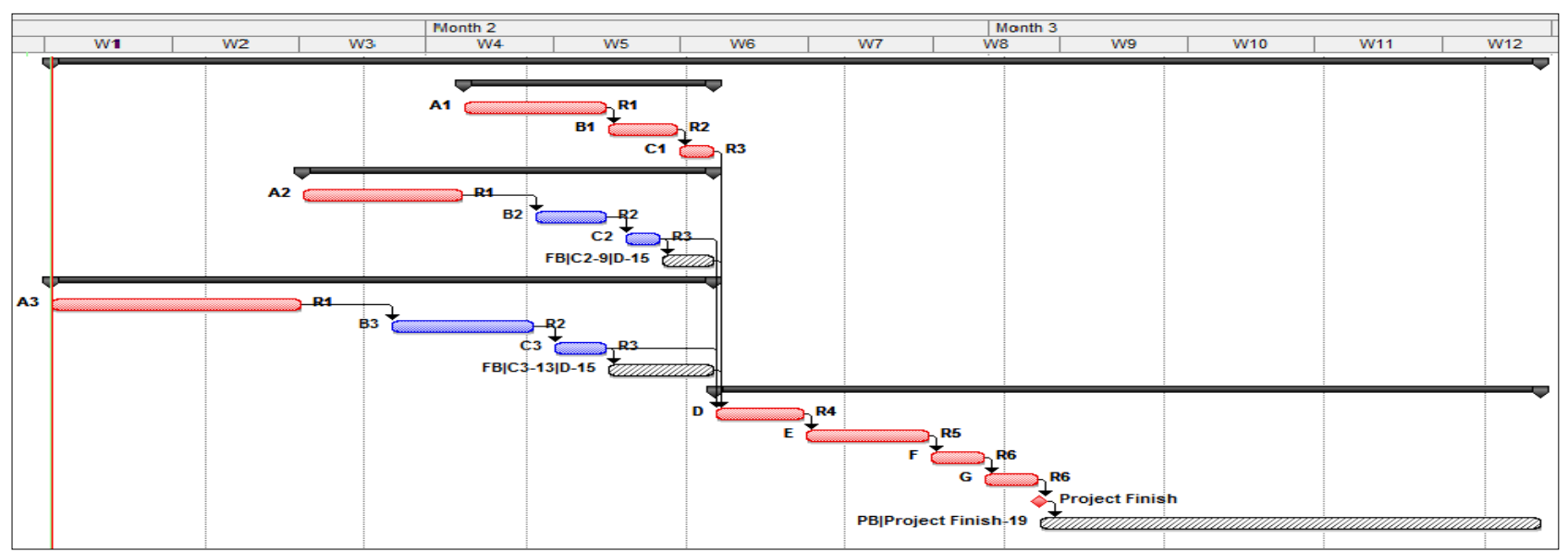

Fig. (3) The Critical Chain Schedule. (Lawrence 2014).

Table (1) utility data for the example problem

\begin{tabular}{|c|c|c|c|c|c|c|c|}
\hline \multirow[b]{3}{*}{ Group } & \multirow{3}{*}{$\begin{array}{c}\text { Activity } \\
\text { Name }\end{array}$} & \multicolumn{6}{|c|}{ Direct Cost } \\
\hline & & \multicolumn{2}{|c|}{ one shift or $1^{\text {st }}$ shift } & \multicolumn{2}{|c|}{ Double shifts or $2^{\text {nd }}$ shift } & \multicolumn{2}{|c|}{ Triple shifts or $3^{\text {rd }}$ shift } \\
\hline & & Duration & Cost & Duration & Cost & Duration & Cost \\
\hline \multirow{3}{*}{ (1) } & Act. A1 & 16 & 100000 & 16 & 105000 & 16 & 110000 \\
\hline & Act. A2 & 17 & 125000 & 17 & 131250 & 17 & 137500 \\
\hline & Act. A3 & 28 & 225000 & 28 & 236250 & 28 & 247500 \\
\hline \multirow{3}{*}{ (2) } & Act B1 & 8 & 82000 & 8 & 86100 & 8 & 90200 \\
\hline & Act. B2 & 8 & 35000 & 8 & 36750 & 8 & 38500 \\
\hline & Act. B3 & 16 & 42000 & 16 & 44100 & 16 & 46200 \\
\hline \multirow{3}{*}{ (3) } & Act. C1 & 4 & 60000 & 4 & 63000 & 4 & 66000 \\
\hline & Act. C2 & 4 & 29000 & 4 & 30450 & 4 & 31900 \\
\hline & Act. C3 & 6 & 36000 & 6 & 37800 & 6 & 39600 \\
\hline \multirow{4}{*}{ (4) } & Act. D & 10 & 9600 & 6 & 12096 & 4 & 12672 \\
\hline & Act. E & 13 & 24000 & 8 & 31015 & 6 & 36554 \\
\hline & Act. $\mathrm{F}$ & 6 & 72000 & 4 & 100800 & 3 & 118800 \\
\hline & Act. $\mathrm{G}$ & 6 & 10000 & 4 & 14000 & 3 & 16500 \\
\hline
\end{tabular}

Table 1 shows that:-

1- Groups (1), (2), and (3) have constrained related activities. \%increase in Cost of the second and third shifts is $5 \%$, and $10 \%$ of first shift. For example activity (A1) has 16 days with cost of LE.100000 in case of execution this activity in the first shift. In case of execution this activity in the second shift, the cost of activity is (100000*1.05=LE.105000). In case of execution this activity in the third shift, the cost of activity is (100000*1.1=LE.110000), 
2- Group (4) has non related activities. \%increase in Cost of the second and third shifts is $10 \%$, and $20 \%$ of first shift. For example activity (D) has 10 days with cost of 9600 in case of execution this activity in one shift. In case of execution this activity in double shifts the cost of activity is $\left(0.6 * 9600+0.6^{*} 9600 * 1.1=\right.$ LE.12096). In case of execution this activity in triple shifts the cost of activity is $\left(0.4^{*} 9600+0.4^{*} 9600 * 1.1+0.4^{*} 9600 * 1.2=\right.$ LE. 12672$)$.

3- Normal cost of the project is the summation of activities normal costs $=$ LE. 849600, and the Project total cost $=849600+425000=$ LE. 1274600 . Project normal duration $=85$ days.

\subsection{MATHEMATICAL STATEMENT OF THE EXAMPLE PROBLEM}

Let the first subscript associated with variables. For example, $\mathrm{X} 3_{\mathrm{A} 1}$ represents the variable belonging to the third discrete point "of activity (A1). SS $\mathrm{A}_{\mathrm{A}}$ represents scheduled start variable of activity (A1). Number of zero-one variables $=39$

No. of activity scheduled start variables $=14$

\section{Minimize:}

$100000 \mathrm{X} 1_{\mathrm{A} 1}+105000 \mathrm{X} 2_{\mathrm{A} 1}+110000 \mathrm{X} 3_{\mathrm{A} 1}+82000 \mathrm{X} 1_{\mathrm{B} 1}$ $+86100 \times 2_{\mathrm{B} 1}+90200 \times 3_{\mathrm{B} 1}+60000 \times 1_{\mathrm{c} 1}+63000 \mathrm{X}_{\mathrm{C} 1}+$ $66000 \mathrm{X} 3_{\mathrm{C} 1}+125000 \mathrm{X}_{\mathrm{A} 2}+131250 \mathrm{X} 2_{\mathrm{A} 2}+137500 \mathrm{X}_{\mathrm{A} 2}$ $+35000 \mathrm{X} 1_{\mathrm{B} 2}+36750 \times 2_{\mathrm{B} 2}+38500 \mathrm{X}_{\mathrm{B} 2}+29000 \mathrm{X} 1_{\mathrm{C} 2}+$ $30450 \mathrm{X} 2 \mathrm{c} 2+31900 \mathrm{X} 3 \mathrm{c} 2+225000 \times 1_{\mathrm{A} 3}+236250 \mathrm{X} 2_{\mathrm{A} 3}$ $+247500 \mathrm{X} 3_{\mathrm{A} 3}+42000 \mathrm{X} 1_{\mathrm{B} 3}+44100 \mathrm{X} 2_{\mathrm{B} 3}+46200 \mathrm{X} 3_{\mathrm{B} 3}$ $+36000 \times 1_{\mathrm{c} 3}+37800 \times 2_{\mathrm{c} 3}+39600 \times 3 \mathrm{c}_{3}+9600 \times 1_{\mathrm{D}}+$ $12096 \times 22_{D}+12672 \times 3_{D}+24000 \times 1_{E}+31015 \times 2_{E}+$ $36554 X 3_{\mathrm{E}}+72000 \mathrm{X} 1_{\mathrm{F}}+100800 \mathrm{X} 2 \mathrm{~F}+118800 \mathrm{X} 3_{\mathrm{F}}+$ $10000 \times 1_{\mathrm{G}}+14000 \mathrm{X}_{\mathrm{G}} \mathrm{G}+16500 \mathrm{X}_{\mathrm{G}}+5000 \mathrm{SF}$

\section{Subject to:}

$\mathrm{X} 1_{\mathrm{A} 1}+\mathrm{X} 2_{\mathrm{A} 1}+\mathrm{X} 3_{\mathrm{A} 1}=1$

$\mathrm{X} 1_{\mathrm{B} 1}+\mathrm{X} 2_{\mathrm{B} 1}+\mathrm{X} 3_{\mathrm{B} 1}=1$

$\mathrm{X} 11_{1}+\mathrm{X}_{\mathrm{C} 1}+\mathrm{X}_{\mathrm{C} 1}=1$

$\mathrm{X} 1_{\mathrm{A} 2}+\mathrm{X} 2_{\mathrm{A} 2}+\mathrm{X} 3_{\mathrm{A} 2}=1$

$\mathrm{X} 1_{\mathrm{B} 2}+\mathrm{X} 2_{\mathrm{B} 2}+\mathrm{X} 3_{\mathrm{B} 2}=1$

$\mathrm{X} 1_{\mathrm{C} 2}+\mathrm{X} 2_{\mathrm{C} 2}+\mathrm{X}_{\mathrm{C}_{2}}=1$

$\mathrm{X} 1_{\mathrm{A} 3}+\mathrm{X} 2_{\mathrm{A} 3}+\mathrm{X} 3_{\mathrm{A} 3}=1$

$\mathrm{X} 1_{\mathrm{B} 3}+\mathrm{X} 2_{\mathrm{B} 3}+\mathrm{X} 3_{\mathrm{B} 3}=1$

$\mathrm{X} 1_{\mathrm{C}_{3}}+\mathrm{X}_{\mathrm{C}_{3}}+\mathrm{X} 3_{\mathrm{C}_{3}}=1$

$X 1_{D}+X 2_{D}+X 3_{D}=1$

$\mathrm{X} 1_{\mathrm{E}}+\mathrm{X} 2_{\mathrm{E}}+\mathrm{X} 3_{\mathrm{E}}=1$

$\mathrm{X} 1_{\mathrm{F}}+\mathrm{X} 2_{\mathrm{F}}+\mathrm{X} 3_{\mathrm{F}}=1$

$\mathrm{X} 1_{\mathrm{G}}+\mathrm{X} 2_{\mathrm{G}}+\mathrm{X} 3_{\mathrm{G}}=1$

$\mathrm{X} 1_{\mathrm{A} 1}+\mathrm{X} 1_{\mathrm{A} 2}+\mathrm{X} 1_{\mathrm{A} 3}=1$

$\mathrm{X} 2_{\mathrm{A} 1}+\mathrm{X} 2_{\mathrm{A} 2}+\mathrm{X} 2_{\mathrm{A} 3}=1$

$\mathrm{X} 3_{\mathrm{A} 1}+\mathrm{X} 3_{\mathrm{A} 2}+\mathrm{X} 3_{\mathrm{A} 3}=1$

$\mathrm{X} 1_{\mathrm{B} 1}+\mathrm{X} 1_{\mathrm{B} 2}+\mathrm{X} 1_{\mathrm{B} 3}=1$

$\mathrm{X} 2_{\mathrm{B} 1}+\mathrm{X} 2_{\mathrm{B} 2}+\mathrm{X} 3_{\mathrm{B} 3}=1$

$\mathrm{X} 3_{\mathrm{B} 1}+\mathrm{X} 3_{\mathrm{B} 2}+\mathrm{X} 3_{\mathrm{B} 3}=1$

$\mathrm{X} 1_{\mathrm{C}_{1}}+\mathrm{X} 1_{\mathrm{C} 2}+\mathrm{X} 1_{\mathrm{c} 3}=1$

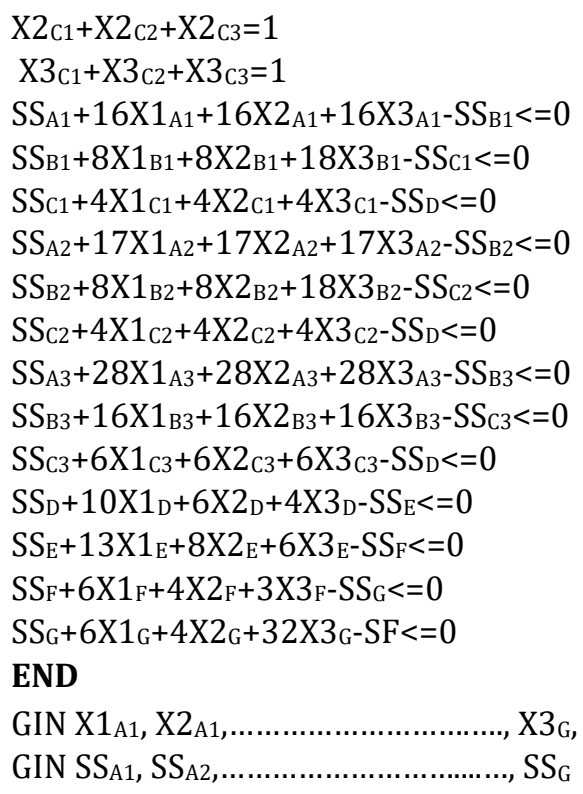

\subsection{THE PROBLEM SOLUTION}

LINGO is used to handle the above optimization problem automatically by finding the answer that yields the best result. Global optimal solution found. Objective value is $\mathbf{1 2 4 7 7 7 6}$. The solution of the model is presented in Table (2).

Solution of integer programming model shows that the most economical solution L.E. 1247776. Project duration is equal to 70 days. Results of durations and start dates of example project activities are showed in Figure (4). 
Table (2) Values of Model Variables for Most Economical Solution.

\begin{tabular}{|c|c|c|c|c|c|}
\hline Variable & Value & Variable & Value & Variable & Value \\
\hline X1A1 & 0.00 & X2A1 & 0.00 & X3A1 & $\mathbf{1 . 0 0}$ \\
\hline X1A2 & 0.00 & X2A2 & $\mathbf{1 . 0 0}$ & X3A2 & 0.00 \\
\hline X1A3 & $\mathbf{1 . 0 0}$ & X2A3 & 0.00 & X3A3 & 0.00 \\
\hline X1B1 & 0.00 & X2 B1 & $\mathbf{1 . 0 0}$ & X3 B1 & 0.00 \\
\hline X1B2 & 0.00 & X2 B2 & 0.00 & X3 B2 & $\mathbf{1 . 0 0}$ \\
\hline X1B3 & $\mathbf{1 . 0 0}$ & X2B3 & 0.00 & X3B3 & 0.00 \\
\hline X1C1 & $\mathbf{1 . 0 0}$ & X2 C1 & 0.00 & X3 C1 & 0.00 \\
\hline X1C2 & 0.00 & X2 C2 & 0.00 & X3 C2 & $\mathbf{1 . 0 0}$ \\
\hline X1C3 & 0.00 & X2C3 & $\mathbf{1 . 0 0}$ & X3C3 & 0.00 \\
\hline X1D & 0.00 & X2D & 0.00 & X3D & $\mathbf{1 . 0 0}$ \\
\hline X1E & 0.00 & X2E & 0.00 & X3E & $\mathbf{1 . 0 0}$ \\
\hline X1F & $\mathbf{1 . 0 0}$ & X2F & 0.00 & X3F & 0.00 \\
\hline X1G & 0.00 & X2G & $\mathbf{1 . 0 0}$ & X3G & 0.00 \\
\hline SSA1 & 0.00 & SSB1 & 16.00 & SSC1 & 24.00 \\
\hline SSA2 & 0.00 & SSB2 & 17.00 & SSC2 & 25.00 \\
\hline SSA3 & 0.00 & SSB3 & 28.00 & SSC3 & 44.00 \\
\hline SSD & 50.00 & SSE & 54.00 & SSF & 60.00 \\
\hline SSG & 66.00 & SF & 70.00 & & \\
\hline
\end{tabular}

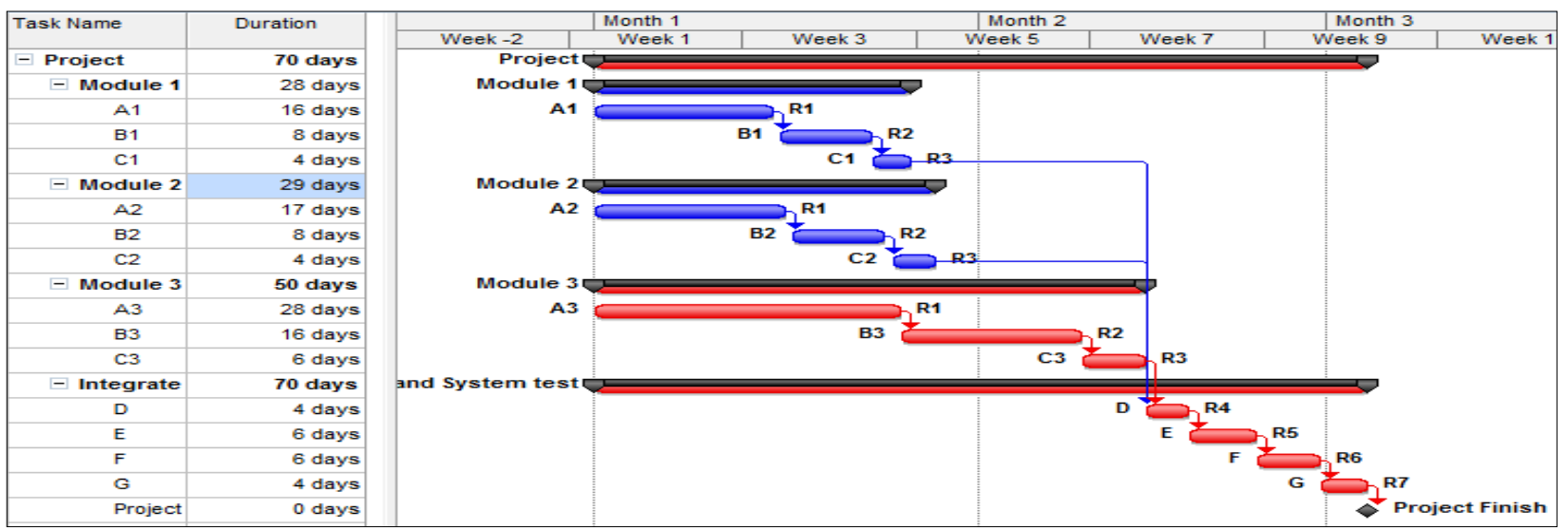

Fig.(4) Output Data of the Example Project by Proposed Model

Figure (4) show that:-

1- Activities (A1, A2, and A3) started at the same date because they use the same resource but activity A1 will be executed in the third shift, activity A2 will be executed in the second shift, and activity $\mathrm{A} 3$ will be executed in the first shift.

2- Activities (B1, B2, and B3) started at the same date because they use the same resource but activity B1 will be executed in the second shift, activity B2 will be executed in the third shift, and activity $\mathrm{B} 3$ will be executed in the first shift.

3- Activities (C1, C2, and C3) started at the same date because they use the same resource but activity $\mathrm{C} 1$ will be executed in the first shift, activity
C2 will be executed in the third shift, and activity C3 will be executed in the second shift.

4- Working in multiple shifts system and increasing labors wages in second and third shifts are a motivation for labors not to waste time and to concentrate on finishing activities in their time. So, multiple shifts can be used to overcome Student's Syndrome and Parkinson's Law

5- Total project duration is minimized from 85 days to 70 days with $17.64 \%$ reduction in project normal duration (85 days) with minimum cost that can be applied in construction projects comparison with CCPM method. 


\section{Summary and Conclusion}

In this paper, a brief review of CCPM and its requirements that do not satisfy construction projects are presented. The proposed model has been developed dealing with optimum duration with minimum cost of construction projects. The problem is formulated using integer programming and utilization of multiple shifts for the activities and constrained related activities in construction projects. The model procedures and final solution of the example problem show that multiple shifts and discrete relationship between activity time and cost are effective and can be applied on large scale projects. They express construction real-life projects and give optimal project duration with minimum cost. Multiple Shifts system is very useful to treat constrained related activities by using each shift for execution of one activity by the same machine. Working in shifts system makes labors to be keen to finish activities in time and prevents to a great extent loss of productivity. So, multiple shifts can be used to overcome Student's Syndrome and Parkinson's Law; principles of CCPM.

\section{References}

1- Goldratt, E.M., "Critical chain" Great Barrington, MA, EUA: North River Press, 1997.

2- Wuliang, P., Hui, S., and Yongping, H., "A genetic algorithm for critical chain project scheduling problem " International Journal of Digital Content Technology and its Applications (JDCTA), Vol. 7, No. 3, February 2013.

3- Leach, L. P., "Critical Chain Project Management" Norwood: ARTECH HOUSE, INC, 2000.

4- Hegazy, T., "Computer-based Construction Project Management" Inform, Prentice Hall, 2002.

5- Debal, T., Slusarczyk, A., Kuchta, D., Verhulst, P., Huyghe, W., and Lauryssen, K., "A Comparison of Buffer Sizing Techniques in The Critical Chain Method. Case Study" Journal of Automation, Mobile Robotics\& Intelligent Systems" Vol. 7 N.3, 2012.

6- Raz,T., "A Critical Look at Critical Chain Project Management." Faculty of Management, Tel Aviv University, New Zealand, Dec, 2001.

7- Sharma, D., and Yadav, S., "A Review Paper on Critical Chain Project Management Method in Construction Project" Journal for Studies in Management and Planning, Vol. 3.Issue 02, ISSN: 2395-0463, 2017.

8- Prajapati, M.P., and Yadav, N.B., "Buffer Based CCPM Scheduling: A Modern Approach for Indian Constraints" International Conference on Research and Innovations in Science, Engineering and Technology, Vol.1, 2017.
9- Peng, W.L., and $\mathrm{Xu}, \mathrm{H}$., "The Scheduling Problem of Active Critical Chain Method," Information Technology Journal, Vol. 11(7), ISSN 1812-5638, 2012.

10- Kendall, G.I., Pitagorsky, G., and Hullet, D., "Integrating Critical Chain and the PMBOK Guide," International Institute for Learning, Inc, 2001.

11- Chen, P. H., and Weng, H., "A two-phase GA model for resource constrained project scheduling." Automation in Construction, Vol. 18, No. 4, pp. 485-498, 2009.

12- Eldosouky, A. I., Abdel Reheem, A. H., and Ammar, M. A., "An Optimization Approach to Project Time-Cost Problem," Fourth Arab Structural Engineering Conference, Cairo, Egypt, Nov., 1991, Part V, PP. V-61:V72.

13- Mayer, W., and Shaffer, L.R., "Extending CPM for Multiform Project Time-Cost Curves, " Journal of the Construction Division, ASCE, Vol. 91, No. C01, pp. 45-67, May 1965.

14- Hanna, A. S., Chang, C., Sullivan, K. T., and Lackney, J. A., "Impact of Shift Work on Labor Productivity for Labor Intensive Contractor." Journal of Construction Engineering and Management, 134(3), 197-204, 2008.

15- Kogi, K., "Temporal Factors in Work Scheduling." Introduction to the problems of shiftwork, Hours of Work, S. Folkard and T. H. Monk, eds., John Wiley \& Sons, New York, 1985.

16- Folkard, S., and Tucker, P., "Shift work, safety and productivity." Occup. Med, 53(2), 95-101, 2003.

17- Penkala, D., "Improving productivity and profitability around the clock." Natl. Prod. Rev., 16(3), 29-35, 1997.

18- Ibbas, W., "Change and the Loss of Productivity in Construction: A Gield Guide." www.TheIbbsConsultingGroup.com. (510) 420-8625, 2015.

19- Waldron, J. A., " Applied principles of project planning and control", Haddonfield, Englewood Cliffs, N.J, 1968.

20- Lindo Systems Inc, Lingo, 2017<www.lindo.com> .

21- Leach, L.P., "Critical Chain Project Management". Third edition, Artech house Inc, Boston, 2014. 